Vol. 1 No. 2, Juni 2021, hlm. $181-186$

DOI: https://doi.org/10.33330/jutsi.v2i1.1175

Available online at http://jurnal.stmikroyal.ac.id/index.php/jutsi

\title{
PERANCANGAN SISTEM PELAPORAN TINDAK KEKERASAN \\ PADA PEREMPUAN DAN ANAK DI DP3A KOTA TANJUNGBALAI
}

\author{
Oni Dewi Lestari ${ }^{1}$, Herman Saputra ${ }^{2 *}$, Elly Rahayu ${ }^{3}$ \\ ${ }^{1}$ Mahasiswa Prodi Sistem Informasi, STMIK Royal \\ ${ }^{2}$ Prodi Sistem Komputer, STMIK Royal \\ ${ }^{3}$ Prodi Sistem Informasi, STMIK Royal \\ *email : hermansaputra4@gmail.com
}

\begin{abstract}
At this time there are still many victims of violence who do not want to report the violence they have experienced because they do not want their identities to be known by others, because it will tarnish their self-respect and because of the complicated reporting mechanism, where the reporter who is going to make a report must come directly. So it is made how to design a violence reporting system and implement PHP and MySQL in it. The methodology used in this research is to first identify problems, study literature, collect data, analyze data, design systems, test systems and implement systems. This violence reporting system can make it easier for reporters to report violence without having to come to the office and it can be concluded that the research has been able to create a reporting system for violence against women and children in DP3A and PMK Tanjungbalai City by implementing the PHP programming language and database MySQL.
\end{abstract}

Keyword : Reporting System; PHP dan MySQL; Violence; DP3A and PMK

\begin{abstract}
Abstrak : Pada saat ini masih banyak korban kekerasan yang tidak ingin untuk melapor kekerasan yang dialaminya karena tidak ingin identitasnya diketahui orang lain, karena akan mencoreng harga dirinya dank arena mekanisme pelaporan yang rumit, dimana pelapor yang akan membuat laporan harus datang langsung. Sehingga dibuat bagaimana merancang sistem pelaporan tindak kekerasan dan menerapkan PHP dan MySQL didalamnya. Metodologi yang digunakan pada penelitian ini adalah terlebih dahulu melakukan identifikasi masalah, studi literature, pengumpulan data, analisis data, perancangan sistem, pengujian sistem dan implementasi sistem. Sistem pelaporan tindak kekerasan ini dapat mempermudah para pelapor dalam melakukan pelaporan tindak kekerasan tanpa harus datang ke kantor dan telah dapat disimpulkan bahwa penelitian telah mampu membuat sebuah sistem pelaporan tindak kekerasan pada perempuan dan anak di DP3A dan PMK Kota Tanjungbalai dengan menerapkan bahasa pemrograman PHP dan database MySQL.
\end{abstract}

Kata Kunci : Sistem Pelaporan; PHP dan MySQL; Tindak Kekerasan; DP3A dan PMK 
Vol. 1 No. 2, Juni 2021, hlm. $181-186$

DOI: https://doi.org/10.33330/jutsi.v2i1.1175

Available online at http://jurnal.stmikroyal.ac.id/index.php/jutsi

\section{PENDAHULUAN}

Kerap terjadi kasus masalah kekerasan kepada para perempuan dan anak saat sekarang merupakan permasalah yang harus mendapatkan kepedulian dari masyarakat maupun pemerintah sekitar. Di masyarakat saat ini sudah kita ketahui bahwa banyak dimana-mana korban tindak kekerasan yang terjadi pada kalangan perempuan dan anak. Anak merupakan tunas bangsa yang memiliki potensi dan sebagai penerus bangsa [1].

Orang yang mengalami kekerasan pada kaum perempuan dan anak memang sangat sedikit atau jarang ditemui di berbagai macam literatur yang ada, dikarena kasus permasalahan ini jarang sekalu terungkap, proses dimana seseorang menjadi korban kejahatan melalui tindak kekerasan yang dilaporkan ke peradilan pidana. Permasalahnya terdapat pada kalangan masyarakat mungkin menurut masyarakat, baik keseluruhannya maupun korban kekerasan tersendiri, bahwa tindak kekerasan yang dialaminya akan lebih baik tidak diketahui orang lain dan diselesaikan sendiri secara kekeluargaan. Meski memiliki kaitan dengan nilai-nilai yang beredar pada masyarakat mengenai kedudukan perempuan selama ini dalam masyarakat.

Kalangan perempuan pada saat ini banyak yang masih menyembunyikan proses dimana seseorang menjadi korban kekerasan kepada dirinya karena banyak pertimbangan, tetapi yang paling utama adalah karena para korban tindak kekerasan tidak mau jika masyarakat mengetahui identitasnya dikarenakan dapat mencoreng martabat seorang perempuan, terlepas dari ada tidaknya sesuatu yang dilakukan perempuan untuk membantu menyelesaikan tindak kekerasan yang dialaminya. Dengan adanya sistem pengaduan ini korban dapat dengan mudah melakukan pelaporan kekerasan tanpa perlu kekantor. Sehingga lebih banyak korban atau masyarakat yang melapor kasus tindak kekerasan tersebut. Kekerasan merupakan suatu ekspresi yang dilakukan oleh individu maupun kelompok di mana secara fisik maupun verbal mencerminkan tindakan agresi dan penyerangan pada kebebasan atau martabat [2].

Undang-Undang Nomor 35 Tahun 2014 tentang Perubahan Atas UndangUndang Nomor 23 Tahun 2002 tentang Perlindungan Anak, mempertegas seharusnya memperberat hukuman pidana dan denda bagi pelaku kekerasan terhadap anak terutama kepada kekerasan seksual yang bertujuan untuk memberikan efek takut sehingga mereka tidak akan melakukan keselahan itu lagi, serta mendorong adanya langkah yang benar untuk memulihkan kembali fisik, psikis dan aktivitas anak. Hal tersebut perlu dilakukan untuk mencegah anak dikemudian hari tidak menjadi pelaku kejahatan yang sama.

Teknologi informasi adalah bagian teknologi yang berkembang sangat pesat di lingkungan modernisasi saat ini. Perkembangan teknologi mempermudah pengguna untuk mendapatkan informasi yang diharapkan secara cepat. Kenggunaannya mencangkup ke berbagai bagian, seperti komunikasi, ekonomi, bisnis, pendidikan, kesehatan dan lain lain. Perkembangan ilmu pengetahuan dan teknologi mempermudah manusia dalam melakukan berbagai kegiatan sehari-hari.

Dalam penelitian ini, peneliti menggunakan bahasa pemrograman $P H P$ dan $M y S Q L$ karena dapat bahasa pemrograman ini mendukung sistem yang dibuat nantinya dapat diakses oleh siapapun tanpa terkecuali, serta memberikan bentuk website yang menarik dan mudah dipahami karena bersifat user friendly [3]. Dinas Pemberdayaan Perempuan, Perlindungan Anak dan Pemberdayaan Masyarakat Kelurahan (DP3A dan 
Vol. 1 No. 2, Juni 2021, hlm. $181-186$

DOI: https://doi.org/10.33330/jutsi.v2i1.1175

Available online at http://jurnal.stmikroyal.ac.id/index.php/jutsi

PMK) Kota Tanjungbalai selama ini bergabung dengan Badan Pemberdayaan Masyarakat Perempuan dan Keluarga Berencana (BPMP dan KB). Pelaporan pada DP3A dan PMK Kota Tanjungbalai ini belum memanfaatkan teknologi karena prosesnya masih manual yang dapat menyebabkan lamanya proses penangan pada korban. Tujuan dari sistem pelaporan tindak kekerasan pada perempuan dan anak adalah untuk mempermudah para korban untuk melaporkan tindak kekerasan yang terjadi tanpa perlu datang ke kantor karena masih banyak korban yang beranggapan jika datang ke kantor akan sulit prosedurnya sehingga banyak yang memilih diam daripada melapor, serta memudahkan petugas untuk menangani kasus dan mendamping korban untuk melapor kekantor polisi, dengan sistem ini petugas juga dapat menemukan data korban secara cepat dan untuk mencegah agar data para korban tidak hilang.

\section{METODE}

Metode penelitian yang digunakan dalam penelitian ini adalah data kualitatif. Data kualitatif merupakan data yang teknik pengolahannya dilakukan dengan melakukan observasi ke Dinas Pemberdayaan Perempuan Perlindungan Anak dan Pemberdayaan Masyarakat Kelurahan Kota Tanjungbalai dan langsung bertanya kepada pihakpihak yang bersangkutan, sehingga mendapatkan jawaban beserta penjelasannya [4]. Agar menyelesaikan penelitian ini dengan baik, penulis melakukan teknik pengumpulan data dengan penelitian lapangan. Penelitian lapangan adalah penelitian dan pengambilan data-data yang diperlukan dengan langsung dari tempat penelitian. Penelitian lapangan dilakukan dengan beberapa cara yaitu wawancara dan pengamatan langsung ke Dinas Pemberdayaan Perempuan Perlindungan Anak dan Pemberdayaan Masyarakat Kelurahan (DP3A dan PMK) Kota Tanjungbalai .

\section{HASIL DAN PEMBAHASAN}

Setelah melalui tahap uji coba sistem, sistem pelaporan tindak kekerasan pada perempuan dan anak yang dibangun telah berhasil menghasilkan sistem yang diperlukan dalam pelaporan tindak kekerasan yaitu data pelapor dan laporan tindak kekerasan tersimpan dalam database. Berikut tampilan awal dari sistem pada gambar 1 .

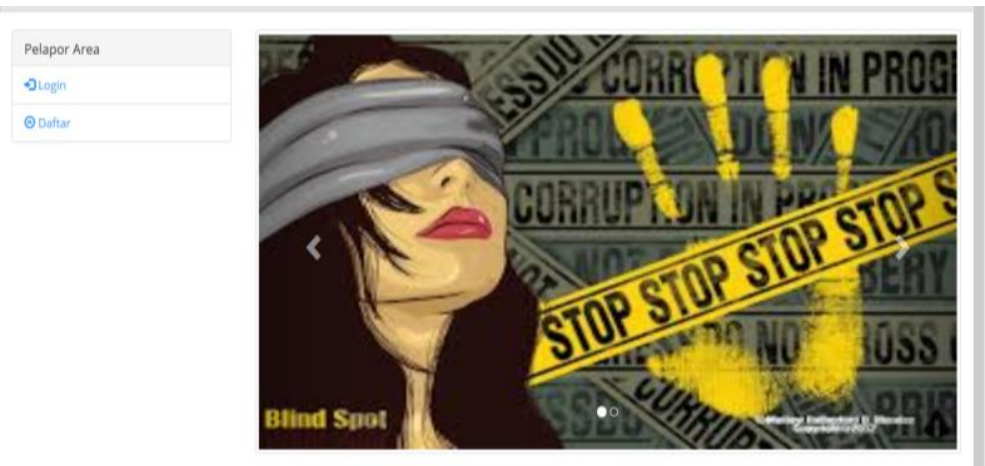

Gambar 1. Tampilan Awal Sistem 
Vol. 1 No. 2, Juni 2021, hlm. $181-186$

DOI: https://doi.org/10.33330/jutsi.v2i1.1175

Available online at http://jurnal.stmikroyal.ac.id/index.php/jutsi

Sebelum melakukan pelaporan tindak kekerasan, terlebih dahulu pelapor harus melakukan registrasi. Berikut tampilannya pada gambar 2.

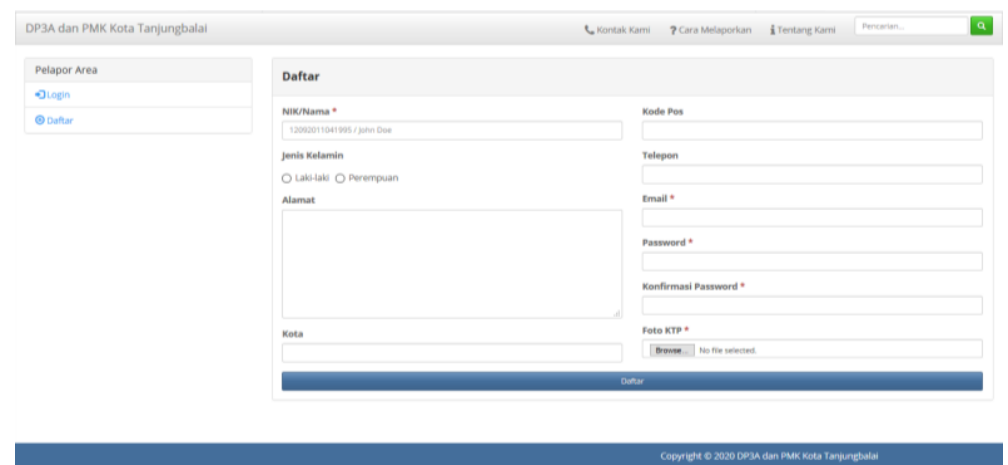

Gambar 2. Tampilan form Registrasi

Selanjutnya untuk masuk ke halaman utama pendaftaran, admin dan user harus login terlebih dahulu jika sudah melakukan registrasi. Berikut tampilannya pada gambar 3.

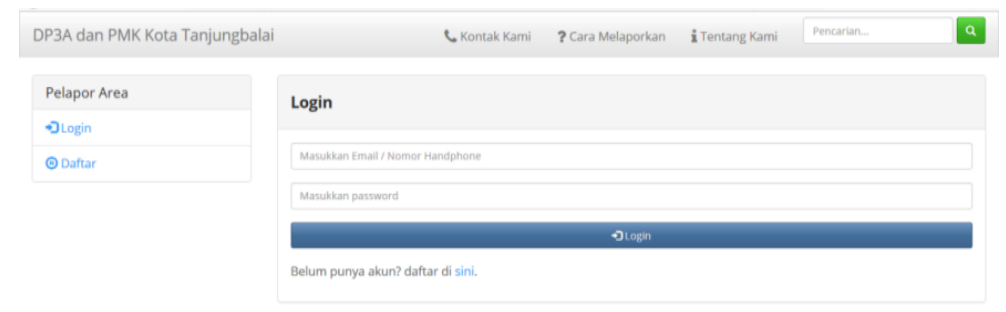

Gambar 3. Tampilan Form Login

Selanjutnya, pelapor yang ingin melakukan pelaporan tindak kekerasan harus memilih menu tindak kekerasan terlebih dahulu. Berikut tampilannya pada gambar 4 .

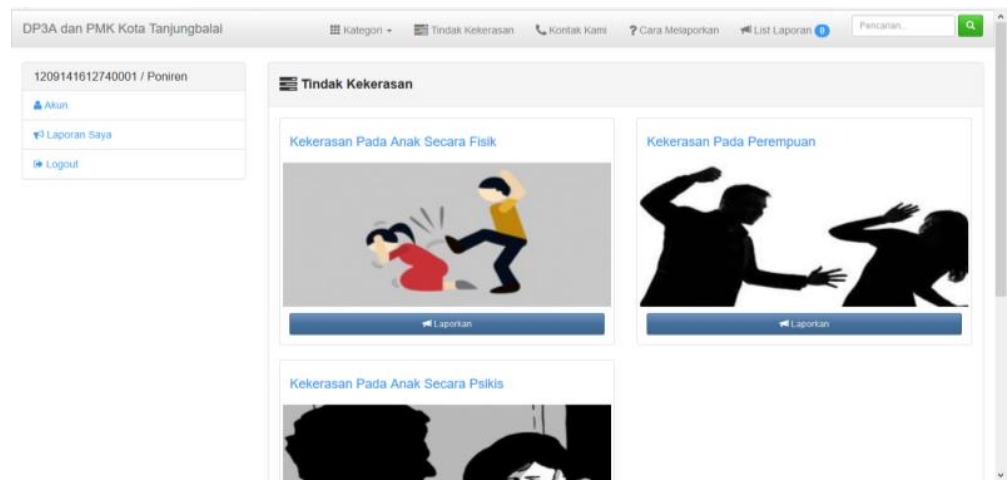

Gambar 4. Menu Tindak Kekerasan 
Vol. 1 No. 2, Juni 2021, hlm. $181-186$

DOI: https://doi.org/10.33330/jutsi.v2i1.1175

Available online at http://jurnal.stmikroyal.ac.id/index.php/jutsi

Kemudian pelapor hanya tinggal memilih tindak kekerasan sesuai yang dialaminya dan melaporkan tindak kekerasan sesuai form tersebut sesuai data yang diminta. Berikut tampilannya pada gambar 5.

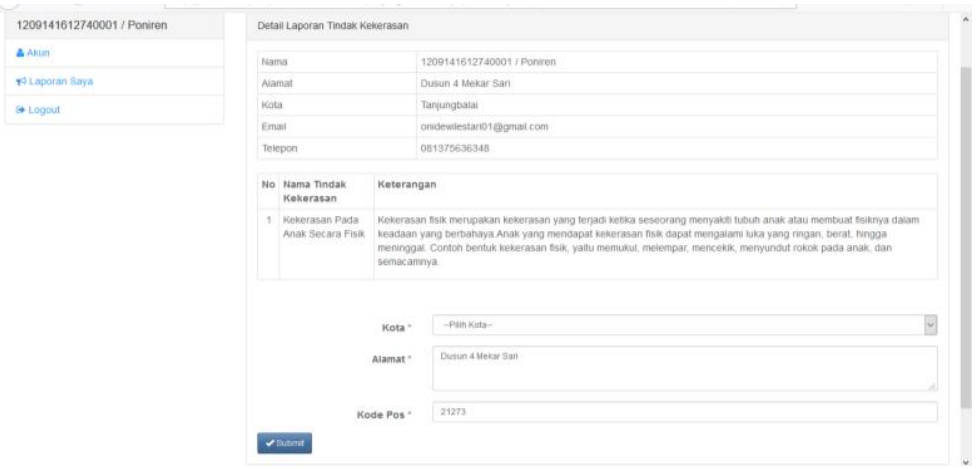

Gambar 5. Tampilan form Input Tindak Kekerasan

Selanjutnya petugas akan melihat detail dari data laporan tindak kekerasan untuk dilakukan pengkonfirmasian laporan. Berikut tampilannya pada gambar 6 .

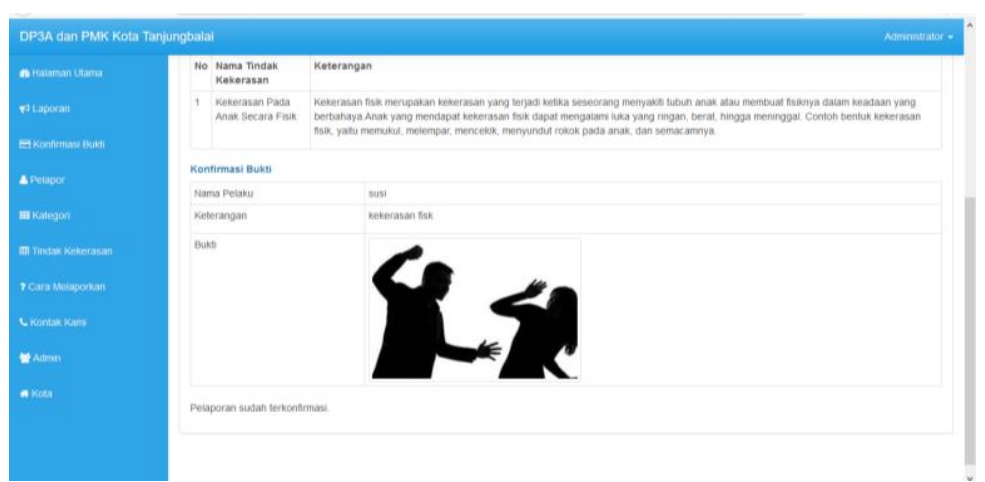

Gambar 6. Tampilan Laporan Sudah Terkonfirmasi

Setelah itu, pelapor mencetak laporan tindak kekerasan. Berikut tampilannya pada gambar 7 .

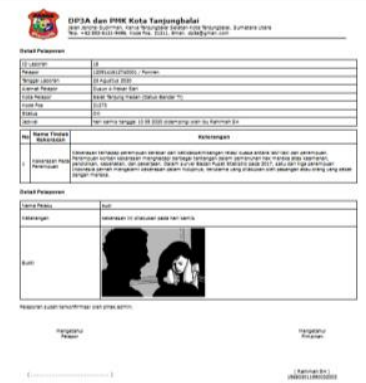

Gambar 7. Tampilan Cetak Laporan 
Vol. 1 No. 2, Juni 2021, hlm. $181-186$

DOI: https://doi.org/10.33330/jutsi.v2i1.1175

Available online at http://jurnal.stmikroyal.ac.id/index.php/jutsi

\section{SIMPULAN}

Berdasarkan hasil implementasi sistem pelaporan tindak kekerasan pada DP3A dan PMK Kota Tanjungbalai, maka dapat diambil suatu kesimpulan bahwa penelitian ini telah mampu merancang dan membuat sistem pelaporan tindak kekerasan pada perempuan dan anak di DP3A dan PMK Kota Tanjungbalai dan menerapkan sistem pelaporan tindak kekerasan untuk mempermudah proses pelaporan tindak kekerasan pada perempuan dan anak di DP3A dan PMK Kota Tanjungbalai dengan menggunakan bahasa pemrograman $P H P$ dan $M y S Q L$.

\section{DAFTAR PUSTAKA}

[1] N. Mulyana, R. Resnawaty, and G. G. K. Basar, "Penanganan anak korban kekerasan," Al-Izzah J. Hasil-Hasil Penelit., vol. 13, no. 1, pp. 77-89, 2018.

[2] Y. Miksilmina, I. Rosyadi, and H. Handayani, "Sistem Informasi Pelaporan Kekerasan Pada Perempuan Dan Anak Berbasis Android ( Studikasus Dinas Pmd P3a Dan Ppkb Kabupaten Pekalongan ),” no. 1, pp. 55-63, 2020.

[3] E. Usada, Y. Yuniarsyah, and N. Rifani, "Rancang Bangun Sistem Informasi Jadwal Perkuliahan Berbasis Jquery Mobile Dengan Menggunakan PHP Dan MySQL," J. INFOTEL - Inform. Telekomun. Elektron., vol. 4, no. 2, p. 40, 2012, doi: 10.20895/infotel.v4i2.107.

[4] F. Ningsih and S. Saifudin, "Peran Audit Internal Dalam Rangka Pencegahan Fraud (Studi Kasus Pt Java Prima Abadi)," Solusi, vol. 17, no. 4, pp. 99-122, 2019, doi: 10.26623/slsi.v17i4.1775. 